\title{
Death and reductionism: a reply to John F Catherwood
}

\author{
David Lamb Manchester University
}

\section{Author's abstract}

This reply to fohn F Catherwood's criticism of brainrelated criteria for death argues that brainstem criteria are neither reductionist nor do they presuppose a materialist theory of mind. Furthermore, it is argued that brain-related criteria are compatible with the majority of religious views concerning death.

John F Catherwood's rigorous and closely argued contribution to the debate on the Danish Council of Ethics' statement on death makes a number of criticisms of brainstem criteria which merit comment $(1,2)$. Catherwood is particularly critical of what he sees as a materialist and reductionist 'translation' of metaphysical concepts to 'an empirical account' of death in earlier contributions to the debate by $\mathrm{Dr}$ Christopher Pallis and myself $(3,4,5,6)$. Whilst I fully endorse Catherwood's excellent argument against reductionism I maintain that the criteria for brainstem death are compatible with most religious and metaphysical standpoints and neither presuppose nor rest on a materialist and reductionist position.

\section{Compatibility of brain death with religious beliefs}

According to Catherwood 'the indicators used in the UK for brain death' - irreversible unconsciousness and irreversible apnoea - are 'accepted neither by many religious bodies, nor by some doctors'. This statement requires more support than Catherwood provides, as he cites only two doctors and no religious authorities (7). In classical philosophy and the major religions death is regarded as the separation of the soul from the body. Yet none of the major religions have devoted close attention to establishing criteria for death. The usual argument is the view expressed by Pope Pius XII, that the determination of death falls outside the competence of the Church. Despite Catherwood's plea that 'arguments over the determination of death be ... left to theologians and philosophers' they have so far failed to describe the concept of the soul and its relation to the body with sufficient precision to furnish

\section{Key words}

Death; brainstem death; reductionism. guidance in clinical decisions. In a clinical context, however, tests for irreversible loss of consciousness and irreversible apnoea can be carried out with precision. Catherwood's argument that 'departure of the soul from the body' cannot be translated as 'loss of the capacity for consciousness' is obviously correct, as he shows with reference to Waismann's theory of language strata. These two expressions belong to different logical and metaphysical realms. Likewise, irreversible cardio-respiratory cessation or total destruction in a nuclear explosion are also irreducible to the separation of the soul from the body. The important question is not whether brain-related criteria for death actually amount to the separation of the soul from the body, but whether they conflict with religious beliefs. On the evidence so far, criteria for brain death have been compatible with Jewish, Roman Catholic, Protestant, Orthodox and Islamic beliefs concerning the nature of death. Over a decade ago the President's Commission in the USA sought testamentary evidence from theologians and concluded that brain-related criteria were compatible with most religious beliefs (8). A similar position applies in European countries with large Protestant and Roman Catholic populations. The state of Israel was one of the first countries in the world to recognise brain-related criteria. Islamic countries have strict regulations concerning the treatment of corpses but do not object to criteria for brain death. The Greek government also recognised brain-death without opposition from the Orthodox Church. Few African religions have addressed the issue but irreversible apnoea would be compatible with their emphasis on 'breath'.

Catherwood's appeal to traditional Japanese religion (where the soul is located in the gut) is scarcely an exception. The ancient Samurai warrior may have committed harakiri by plunging his sword into his belly, not his heart or brain, but his colleagues nevertheless practised decapitation in the knowledge that an enemy without a brain attached to his body was a dead enemy.

The claim that criteria for brainstem death are compatible with religious beliefs is not equivalent to the attempt to reduce religious discourse to a materialist account of the brain. Two logically distinct standpoints can be compatible without being identical. 
Labour MPs who do not oppose the Government are still members of the Opposition.

\section{Brain death and alternative concepts of death}

Catherwood's charge of reductionism is misplaced in his reading of Pallis's claim that 'all death is, and always has been brain death'. For Catherwood this suggests that 'many other uses of the word "death" are either incorrect, inexact, or non-factual, metaphysical expressions', and is a denial that there are other concepts of death than the biological one. Attention to the context in which Pallis's remark is made suggests a different reading. It refers strictly to the mechanism of death and is not to be taken as a dismissal of other forms of discourse about death. In the $A B C$ of Brainstem Death, where Pallis argues that the discussion about the definition of death is primarily a philosophical matter, he provides a list of alternative concepts and related criteria for death from cultures as diverse as medieval Europe and India, thus anticipating Catherwood's remark that 'every culture has a range of accounts of what death is'. The case for brainstem death was not built on a denial of alternative concepts of death but in the awareness that some concepts of death are more meaningful in response to the problems generated by modern medical science. For example, criteria fulfilling a concept of death based on exogamy may be relevant in some cultural contexts and of interest to anthropologists, but are meaningless in an intensive care unit (ICU). This is not, however, a claim that esoteric concepts of death must be reducible to brain-related concepts. Oscar Wilde's poetic insight that 'cowards die a thousand deaths' is unaffected by medical knowledge that total brain infarction is irreversible.

\section{Dogs, frogs and human beings}

According to Catherwood, the definition of death formulated as 'the irreversible loss of function of the organism as a whole', expresses a form of reductionist materialism based on an 'assumption that a human being is merely an organism functioning in an integrated manner'. Consequently he claims that this definition obscures any meaningful distinction between humans, dogs and frogs.

There are no grounds for this inference. The definition simply highlights basic physical processes for doctors to observe in the context of diagnosing death in an ICU when the patient is in an apnoeic coma having sustained serious head injury and is incapable of meaningful interaction with other human beings and the environment. Insofar as it serves to relate a concept of death to certain physical processes it expresses a universality which extends to many different living beings on this planet. The concept of brain death, when formulated as the 'irreversible loss of integrated function of the organism as a whole', refers to the mechanism of death and provides recognisable criteria for death which extend to many different species. But Catherwood's charge that the definition is materialist and that it blurs the distinction between the deaths of humans, dogs and frogs, misses the point. In the passage he takes issue with, my comparison between humans and dogs (I do not recall speaking of frogs) was qualified as follows: 'In these purely biological aspects the death of a human is no different from the death of a dog' (9). The reference to 'purely biological aspects' was not a plea for biological reductionism; it was simply a way of highlighting certain features which are more relevant than others in the appropriate context. Other modes of death discourse remain unaffected. If, for example, moral features are uppermost one can say, without contradicting the previous remark, that the death of a human is radically different from the death of a dog.

Catherwood's confusion here is understandable and can be remedied with reference to a distinction between the mechanism of death and the way we attend to death. The scientific case for brainstem death is primarily based on an appeal to the mechanism of death; it is the death of the critical system without which integrated functioning of component organs is impossible. How we attend to death is, as Catherwood recognises, a far wider issue. The death of Lord Marchmain, dramatically portrayed by Sir Laurence Olivier in the TV production of Brideshead Revisited, could not be performed by a dog because we do not attend to the death of dogs in such a manner. And when Joseph K's death in Kafka's The Trial is compared with the death of a dog we are reminded of the moral significance attached to the way we attend to the death of a human being. Whether or not we should endow the distinction between the deaths of humans and dogs with such metaphysical significance is a question which ethicists might address. Experience with working dogs leads me to question the confidence with which Catherwood denies moral significance to the lives of dogs.

\section{Conclusion}

Brainstem death, as Catherwood notes, is based on empirical criteria. This does not mean that essential philosophical matters have been reduced to medical facts. It means that the brainstem definition of death quite rightly indicates certain functions whose irreversible cessation is compatible with death. The preference for a biological concept is bound up with the requirement for universality and philosophical and moral demands for unambiguous criteria for diagnosing death. To opt for an empirical concept of death is still a philosophical choice, namely that empirical criteria provide the best means of determining death. I do not claim, as Catherwood suggests, that death can be discovered 'independent of our moral viewpoints'. There are moral reasons for preferring a brain-related concept: predictions of irreversibility, accuracy in applying the criteria, and the fulfilment of political, legal and social requirements for a determinate boundary between the living and the dead. At a fundamental level the case for 
a brain-related concept of death, formulated as the irreversible loss of function of the organism as a whole, is based on a holistic view of humankind in keeping with Judaeo-Christian and humanistic ideas.

David Lamb, BA, PhD, is Senior Lecturer in Philosophy at the University of Manchester. He is the author of Death, Brain Death and Ethics, 1985, Down the Slippery Slope, 1988, and Ethics and Organ Transplants, 1990.

\section{References}

(1) Catherwood J F. Rosencrantz and Guildenstern are 'dead'? Journal of medical ethics 1992; 18: 35-39.

(2) Rix B A. Danish Council of Ethics rejects brain death criterion of death. Fournal of medical ethics 1990; 16: 5-7.
(3) Pallis C. Return to Elsinore. Fournal of medical ethics 1990; 16: 10-13.

(4) Pallis C. ABC of brainstem death. London: British medical journal, 1983.

(5) Lamb D. Wanting it both ways. Fournal of medical ethics $\overline{\bar{ज}}$ 1990; 16: 8-9.

(6) Lamb D. Brain death and brainstem death: philosophical and ethical considerations. In: Evans J D G, ed. Moral philosophy and contemporary problems. Royal Institute of Philosophy Series. Cambridge: Cambridge University Press, 1988: 231-249.

(7) Evans D W, Hill D J. The brainstems of organ donors are not dead. Catholic medical quarterly 1989; XL, 3, (243): 113-121.

(8) President's Commission For The Study of Ethical Problems in Medicine and Biomedical and Behavioural Research. Defining death. Washington: US Government Printing Office, 1981: 9-12.

(9) See reference (6): 242. 